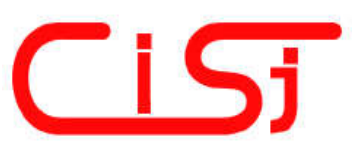

\title{
MODEL OF HUMAN WEIGHT CORRECTION BASED ON INTERVAL DATA ANALYSIS
}

\author{
Svitlana Krepych, Iryna Spivak \\ Department of Computer Science, Ternopil National Economic University \\ 8 Chehova Street, Ternopil, 46003, Ukraine \\ s.krepych@tneu.edu.ua, spivak.iruna@gmail.com
}

Paper history:

Received 15 March 2018

Received in revised form 3 October 2020

Accepted 24 February 2020

Available online 31 March 2020

Keywords:

weight correction model;

interval data analysis;

random parameters search methods.

\begin{abstract}
Scientists have been engaged in research on issues of excessive person's body weight, which causes the obesity problem, for a long time. At the beginning of the 20th century the obesity problem was admitted as a medical illness. Therefore, the study of this problem and the search for solutions to it are an urgent task. At the same time, overweight people are reluctant to see doctorsdietitians due to many circumstances. They usually look for easy ways to solve their problems, and nowadays, one of these ways is the global network Internet. However, in the Internet one can only find websites with information about the caloric content of products, obesity problems, different kinds of diet, etc. The development of special software product that would allow us to simulate the process of weight loss and on its basis to automatically develop the "individual" diet is an urgent task.
\end{abstract}

Copyright $@$ Research Institute for Intelligent Computer Systems, 2020. All rights reserved.

\section{INTRODUCTION}

The problem of overweight of people of all ages is and will be actual in the future. The problem of a particular diet has been existing for many years, though not in such a systematic form in which it is known today. The first medical document that contained a description of a diabetic diet was dated $1550 \mathrm{BC}$ [1]. And for many centuries, hundreds, if not thousands, programs of weight loss were offered, but before the nineteenth century there was no real relation between eating and health. Around 1900, insurance companies announced the existence of a relationship between completeness and mortality, and the concepts of obesity and bad health were closely interrelated in the public consciousness [2]. And, finally, by the beginning of the twentieth century, the overweight was considered a disease requiring treatment [3]. Unfortunately, this problem exists and progresses.

The other side of this problem is that majority of obese people arereluctant to see doctors-dietitians due to many circumstances [3]. In modern life, the material aspect, which requires the provision of funds for people and their families is put forward to the first place, and the question of their health is shifted to the second or possibly to the third plan.

However, the rapid development of computer technologies and information systems has already improved the work conditions in many spheres of human activity, including medical. Therefore, it is expedient and actual to develop a software package for modeling the body weight correction on the basis of the analysis of existing methods of human weight correction, taking into account the methods of interval data analysis.

\section{PROBLEM STATEMENT OF PROCESS OF BODY WEIGHT CORRECTION}

As already noted above, the problem of obesity, which is already admitted as a disease, is widespread in the world and is growing more dynamic. The science magazine The Lancet published disturbing statistics - in 2025, one fifth of the Earth's population would be overweight. The most obesity nations are Chinese and Americans [4]. In Ukraine, obesity affects $22.1 \%$ of the population. Although this is not the worst indicator for Europe (British takes the first place in the obesity problem), however 
almost a quarter of the population with obesity is unsatisfactory indicator.

Figs. 1 and 2 show the percentage level of change in the obesity among the female half of humanity, which illustrates once again the complexity of the situation.

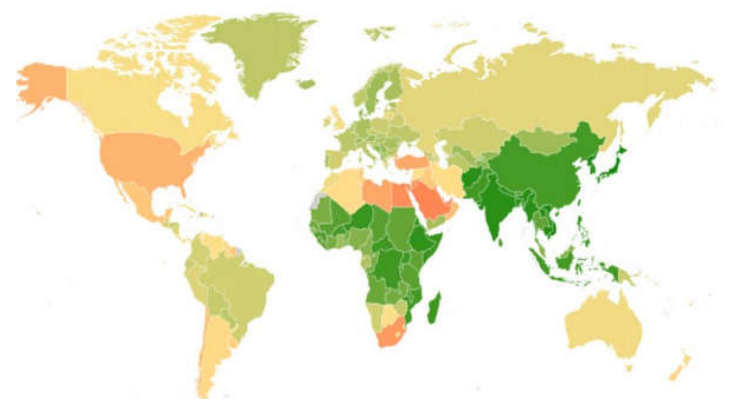

Figure 1 - World's obesity rates for 2014

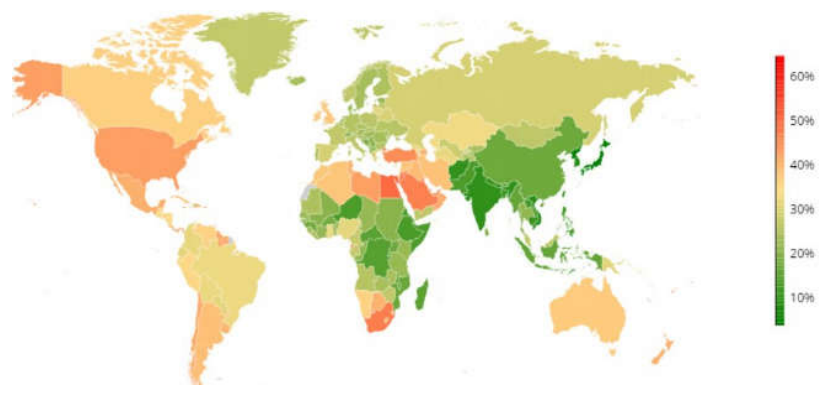

Figure 2 - Forecast of obesity among women of the world by 2025

Consider the existing methods and tools for estimation of human overweight. Table 1 presents the existing methods for estimating the ideal weight of a human body of $168 \mathrm{~cm}$ height and $56 \mathrm{~kg}$ weigh.

Table 1. Methods for estimating the ideal weight of a human body.

\begin{tabular}{|c|c|c|c|}
\hline Estimating formula & Obtained index & Difficulty & Accuracy \\
\hline Lorenz's formula & $(168-100)-\left(\frac{168-150}{2}\right)=59$ & low & low \\
\hline Brock's formula & $(168-105) * 0,89=56,07$ & low & average \\
\hline Body weight index & $I M T=\frac{56}{1,68^{2}}=19,84$ & low & \\
\hline & $168-152,4=15,6 \rightarrow 45 \mathrm{~kg}$ & & high \\
& $15,6-2,45=13,15 \rightarrow 46,9 \mathrm{~kg}$ & & \\
& $13,15-2,45=10,7 \rightarrow 47,8 \mathrm{~kg}$ & & \\
Nagler's formula & $10,7-2,45=8,25 \rightarrow 48,7 \mathrm{~kg}$ & high & \\
& $8,25-2,45=5,8 \rightarrow 49,6 \mathrm{~kg}$ & & \\
& $5,8-2,45=3,25 \rightarrow 50,5 \mathrm{~kg}$ & & \\
& $3,25-2,45=0,8 \rightarrow 51,4 \mathrm{~kg}$ & & \\
& $51,4 * 1,1=56,54 \mathrm{~kg}$ & & \\
\hline
\end{tabular}

According to the Mifflin-St Jeor formula [5], to calculate the daily calorie intake, we need to know our metabolic rate, which is determined by the individual formulas for men and women:

$$
\begin{gathered}
\text { Women }=10 \cdot a+6,25 \cdot b-5 \cdot c-161, \\
\text { Men }=10 \cdot a+6,25 \cdot b-5 \cdot c+5
\end{gathered}
$$

where $a$ - body weight in kilograms; $b$ - height in centimeters; $c$ - age in years.

After calculations, the obtained result must be multiplied by the daily activity coefficient, which depends on the physical activity degree. Below, in Table 2, the value of the physical activity coefficient for various physical activities is given [6-7].
Table 2. The values of the physical activity coefficient [6].

\begin{tabular}{|c|c|}
\hline Type of activity & Value \\
\hline $\begin{array}{c}\text { Minimum loads } \\
\text { (sedentary work) }\end{array}$ & 1,2 \\
\hline $\begin{array}{c}\text { Lightly activity and } \\
\text { light sport exercises 1-3 } \\
\text { times a week }\end{array}$ & 1,375 \\
\hline $\begin{array}{c}\text { Sport exercises 4-5 } \\
\text { times a week (or moderate } \\
\text { intensity work) }\end{array}$ & 1,4625 \\
\hline $\begin{array}{c}\text { Intensive sport } \\
\text { exercises 4-5 times a week }\end{array}$ & 1,550 \\
\hline Daily workout & 1,6325 \\
\hline $\begin{array}{c}\text { Daily intensive } \\
\text { workout or sport exercises } \\
\text { 2 times a day }\end{array}$ & 1,725 \\
\hline $\begin{array}{c}\text { Heavy physical work or } \\
\text { intensive sport exercises 2 } \\
\text { times a day }\end{array}$ & 1,9 \\
\hline
\end{tabular}


Consequently, the Mifflin-St Jeor formula [5] and the physical activity coefficient [6] are the most effective in the process of the body weight correction. However, their significant drawback is that they determine the single value of the daily calorie intake that a person should use, which is inappropriate for use in future calculations, since a person can't $100 \%$ confidently say that his physical activity is 1.9, and the daily calorie norm for this activity will be $2660 \mathrm{Kcal}$. Therefore, for calculation accuracy, it would be more expedient to take these parameters with a certain error at least $15 \%$, and to calculate the correct values of the body weight parameters correction process, we must be using the methods of interval data analysis [8-12], which include the calculation of the required indicators with certain deviations.

Other side of the problem of body weight correcting is that there is no one publicly available tool which allows simulating the process of body weight correcting. There are many Internet services that allow us to properly distribute the process of consumption and calorie loss. However, most of them offer only a variety of diets and calculations of surplus calories in the human body. And given the fact that absolutely all people have the access to the Internet, it is expedient to develop a software package that would simulate the process of body weight correction and provide recommendations for the normalization of body weight or even offer a suitable diet, based on the proposed model. Besides, this software complex can only be used by people from 18 to 45 years of age without congenital, chronic or serious illness.

\section{METHOD OF MODELING HUMAN WEIGHT CORRECTION PROCESSES WITH OPTIMIZATION OF THEIR PARAMETERS ON THE BASIS OF INTERVAL DATA ANALYSIS}

Consider the process of human weight correction in the form of black box [13-15]. Input variables for such model are the values of the coefficients of person physical activity, which are determined by the person according to tabular data, depending on the level of his physical activity for a certain time, the process parameters are respectively the current height and weight of the person, the norm of calorie loss which are required for human weight, the average calorie loss during the day. Output characteristic is the daily person calorie usage.

Let us consider the problem statement of modeling the human body correction process, taking into account the limitations on its initial characteristics, which are mainly nonlinear in parameters. Characteristics of the process, as already noted above, may be an indicator of the daily person calorie usage, etc. In this case, each $i$-th characteristic of the $y_{i}$ correction process is a function of the parameters $\vec{b}=\left(b_{1}, \ldots, b_{j}, \ldots, b_{m}\right)^{T}$ process elements. Mainly in the study of the systems functioning or some processes, nonlinear dependences of the output characteristics of the process on its parameters are used, that is, each $i$-th characteristic $y_{i}, i=1, . ., N$ is a function $g_{i}(\vec{b})$ vector of argument parameters $\vec{b}=\left(b_{1}, \ldots, b_{m}\right)^{T}$. In the process of characteristics simulation, it is advisable to put these process characteristics in an interval form considering the given tolerances:

$$
\left[y_{i}^{-}, y_{i}^{+}\right], i=1, \ldots, N \text {. }
$$

In the case of known dependencies $g_{i}(\vec{b})$ between the values of parameters and output characteristics, and taking into account the limitations (3), we obtain:

$$
y_{i}^{-} \leq g_{i}(\vec{b}) \leq y_{i}^{+}, i=1, \ldots, N
$$

where $\left[y_{i}^{-}, y_{i}^{+}\right]$- limitation intervals on the value of the output characteristics of the system.

According to the system (4), the conditions for coordination of the modeling characteristics values to the experimentally measured are formulated as follows:

$$
g_{i}(\vec{b}) \subset\left[y_{i}^{-}, y_{i}^{+}\right], i=1, \ldots, N \text {. }
$$

The interval system (4) is complicated due to the nonlinearity of the obtained equations. Therefore, for its solution, it is advisable to construct the task function [12]:

$$
F\left(\vec{b}_{k}\right) \stackrel{\vec{b}}{\longrightarrow} \min , \hat{\vec{b}} \in \Psi,
$$


where $\hat{\vec{b}}$ - vector of parameter estimators; $\Psi$ - the area of parameters, which is determined by the physical content of the parameters; $F\left(\vec{b}_{k}\right)$ - task function value of the estimation of the vector of parameters.

In this case, the procedure of estimating the vector of process parameters must be organized in such a way as to ensure reduction of the task function values by the least possible number of iterations $\mathrm{k}=\mathrm{K}$.

The task function of estimating the parameter vector $F\left(\vec{b}_{k}\right)$ will be determined as the difference between the values of the output characteristics of the process found in the process of the ISNAE solution and the centers of the specified intervals of limitations on the output characteristics. Formally, this condition is written in the following form:

$$
F\left(\vec{b}_{k}\right)=\min _{i=1, \ldots, N}\left\{\left|g_{i}(\hat{\vec{b}})-\operatorname{mid}\left(\left[y_{i}\right]\right)\right|\right\},
$$

where $g_{i}(\overrightarrow{\vec{b}})$-the output characteristics calculated during the solution of the interval system of nonlinear algebraic equations on the current iteration; $\left[y_{i}\right]=\left[y_{i}^{-}, y_{i}^{+}\right] ; \quad \operatorname{mid}(\bullet)$ - operation of determining the center of interval.

Figure 3 shows a graphical illustration of calculating the value of the task function (7).

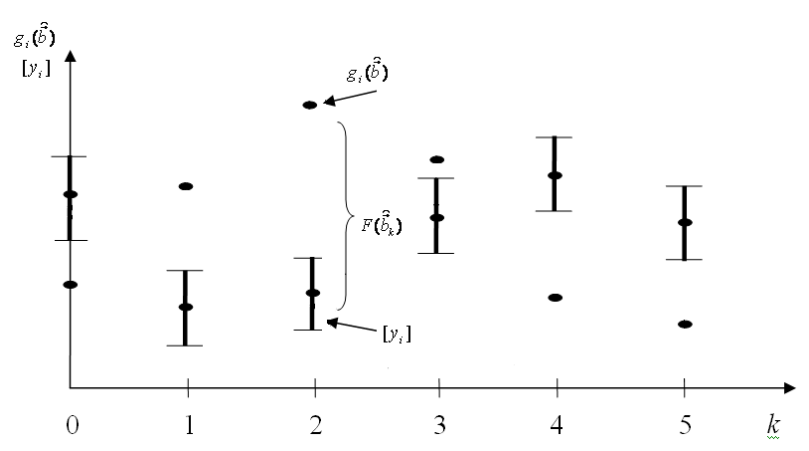

Figure 3 - Illustration for calculating the task function

Obviously, the greater the number of equations in the interval system (4), the more difficult it is to find an ISNAE solution. This task is classified as NPcomplete tasks. The most popular methods for finding a vector of unknown parameters are methods of random search. The main feature of these methods is that in the process of calculating the approximation $\overline{\vec{b}}$ the random vectors are used as a motion direction [16-18]. Finding a better vector of parameters continues until the task function value decreases. If it is not possible to find a point which reduces the task function value on a certain iteration of the random search algorithm among the generated points, then it is advisable to apply an adaptive random value search algorithm with a variable step (radius of search).

There are a large number of methods for random search of the optimal parameters vector, which are described in the L. Rastrigin works. Adaptation of these methods to finding an optimal parameters vector using the methods of interval data analysis was described in detail in the works of M. Dyvak [19,20], S. Krepych [19], I. Spivak [19], and others. In particular, in S. Krepych's work [19] comparative characteristics of the difficulties of implementation of these methods on the basis of the functional suitability estimation of the REC with the tolerance deviations determination for the initial characteristics values and optimization of the REC parameters with their tolerances were described. The expediency of application of random search methods using a guide cone to the problems of modeling systems and processes based on the interval data analysis is proved.

\section{INTERVAL MODEL OF THE PROCESS OF BODY WEIGHT CORRECTION}

To construct an interval model, the studywas conducted on the process of overweight loss in two test groups - men and women. The daily calorie intake was calculated for each representative of the group according to the Mifflin-St Jeor formula and the physical activity coefficient with a relative error $15 \%$. As a result, the initial characteristic of the daily norm of calorie intake is presented in an interval form:

$\left[\tilde{C} d_{A_{i}}^{-} ; \tilde{C} d_{A_{i}}^{+}\right]=\left[C d_{A_{i}}-C d_{A_{i}} \cdot \delta_{C d} ; C d_{A_{i}}+C d_{A_{i}} \cdot \delta_{C d}\right],(8)$

where $C d_{A_{i}}, \delta_{C d}$ - the measured value of daily calorie norm and relative error of its measurement.

Other characteristics are set with errors which can be ignored when building the model. For example, human height measured up to $5 \mathrm{~mm}$, and weight up to 500 grams, which in percentage terms is a maximum of $0,3 \%$ and $0,8 \%$. As the result, we have Table 3 of the output data, the fragment of which is given below. 
Table 3. Measurement of daily calorie intake.

\begin{tabular}{|c|c|c|c|c|c|c|}
\hline № & $\begin{array}{l}\text { Height } \\
\mathrm{h}, \mathrm{sm}\end{array}$ & $\begin{array}{l}\text { Weight } \\
\text { w, kg }\end{array}$ & $\begin{array}{c}\text { Average loss } \\
\text { calories during the } \\
\text { day } \\
\mathrm{Cm}, \mathrm{Kcal}\end{array}$ & $\begin{array}{l}\text { Number of days } \\
\text { required for } \\
\text { weight loss } \\
\text { D, days }\end{array}$ & $\begin{array}{c}\text { Physical activity } \\
\text { coefficient } \\
\text { A }\end{array}$ & $\begin{array}{l}\text { Daily norm calories } \\
\text { Cd, Kcal }\end{array}$ \\
\hline 1 & 150 & 62 & 1430 & 65 & 1,55 & {$[1822,6 ; 2227,6]$} \\
\hline 2 & 151 & 57 & 438 & 126 & 1,2 & {$[1363,8 ; 1666,8]$} \\
\hline 3 & 152 & 60 & 627 & 108 & 1,375 & {$[1601,3 ; 1957,2]$} \\
\hline 4 & 153 & 64 & 882 & 108 & 1,4625 & {$[1764,1 ; 2156,2]$} \\
\hline 5 & 154 & 57 & 1473 & 20 & 1,55 & {$[1773,7 ; 2167,9]$} \\
\hline 6 & 155 & 60 & 920 & 48 & 1,4625 & {$[1721,3 ; 2103,8]$} \\
\hline 7 & 155 & 64 & 1385 & 55 & 1,55 & {$[1873,1 ; 2289,4]$} \\
\hline 8 & 158 & 65 & 324 & 72 & 1,2 & {$[1492 ; 1823,6]$} \\
\hline 9 & 159 & 75 & 419 & 234 & 1,375 & {$[1834,9 ; 2242,7]$} \\
\hline 10 & 160 & 72 & 461 & 136 & 1,375 & {$[1787 ; 2184,1]$} \\
\hline 11 & 161 & 68 & 1289 & 24 & 1,55 & {$[1981,3 ; 2421,5]$} \\
\hline 12 & 162 & 81 & 1126 & 112 & 1,55 & {$[2164,3 ; 2645,3]$} \\
\hline 13 & 163 & 70 & 265 & 116 & 1,2 & {$[1558,2 ; 1904,4]$} \\
\hline 14 & 164 & 86 & 280 & 550 & 1,375 & {$[1991,1 ; 2433,6]$} \\
\hline 15 & 165 & 72 & 1524 & 25 & 1,6325 & {$[2166,8 ; 2648,3]$} \\
\hline 16 & 167 & 79 & 159 & 480 & 1,2 & {$[1677 ; 2049,6]$} \\
\hline 17 & 169 & 85 & 1712 & 63 & 1,725 & {$[2515,4 ; 3074,4]$} \\
\hline 18 & 170 & 99 & 390 & 390 & 1,4625 & {$[2318,6 ; 2833,8]$} \\
\hline 19 & 171 & 77 & 1131 & 28 & 1,55 & {$[2159,1 ; 2638,9]$} \\
\hline 20 & 172 & 85 & 2060 & 44 & 1,9 & {$[2802,7 ; 3425,5]$} \\
\hline 21 & 173 & 92 & 1597 & 85 & 1,725 & {$[2647,4 ; 3225,7]$} \\
\hline 22 & 175 & 80 & 599 & 52 & 1,4625 & {$[2083,3 ; 2546,2]$} \\
\hline 23 & 176 & 99 & 375 & 451 & 1,4625 & {$[2290 ; 2798,9]$} \\
\hline 24 & 177 & 84 & 1686 & 27 & 1,725 & {$[2546,5 ; 3112,4]$} \\
\hline 25 & 178 & 81 & 288 & 52 & 1,375 & {$[1981,9 ; 2422,3]$} \\
\hline 26 & 179 & 85 & 1014 & 28 & 1,55 & {$[2291,6 ; 2800,9]$} \\
\hline 27 & 179 & 109 & 716 & 308 & 1,55 & {$[2626,4 ; 3210,1]$} \\
\hline 28 & 180 & 88 & 1257 & 36 & 1,6325 & {$[2467,1 ; 3015,3]$} \\
\hline 29 & 180 & 105 & 1035 & 161 & 1,6325 & {$[2717,6 ; 3321,5]$} \\
\hline
\end{tabular}

At the first stage of constructing a mathematical model, we selected the linear structure of the model in this form:

$$
\begin{aligned}
& \hat{C} d_{A_{i}}=k_{1} \cdot h+k_{2} \cdot w+k_{3} \cdot C m+ \\
& +k_{4} \cdot D+k_{5} \cdot A_{i}+k_{6}
\end{aligned}
$$

where $k_{i}, i=\overline{1 . .7}-$ unknown coefficients, the values of which need to be estimated based on the analysis of interval data shown in Table 3.
Using the data of the table, we will make ISLAE in the form (10).

The solution to the system (10) is the area of the model coefficients. It is advisable to approximate this area by a multidimensional rectangular parallelepiped drawn around this area. In this case, the coefficients of the model will be presented in interval form. 


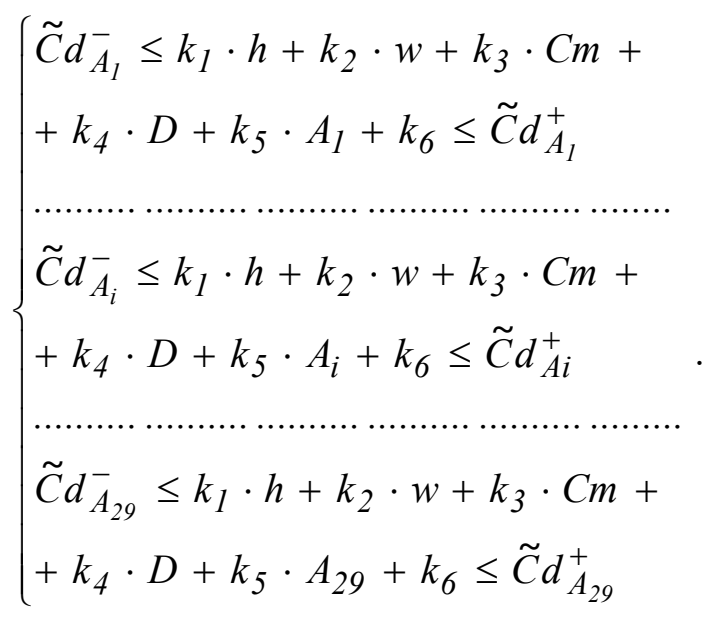

Using the method of interval data analysis to find interval estimates for the ISLAE model coefficients (10), we obtain an interval model:

$$
\begin{aligned}
& {\left[\widehat{C} d_{A_{i}}^{-} ; \widehat{C} d_{A_{i}}^{+}\right]=[4,17 ; 4,43] \cdot h+[16,94 ; 17,99] \cdot w+} \\
& +[0,07 ; 0,08] \cdot C m-[1,2 ; 1,8] \cdot D+ \\
& +[1204,9 ; 1279,5] \cdot A_{i}-[1738,6 ; 1739,9] .
\end{aligned}
$$

The obtained model provides the calculation of the guaranteed interval estimation of daily calorie norm for the given anthropometric data of the human body.

\section{SOFTWARE FOR CONSTRUCTING THE MODEL OF BODY WEIGHT CORRECTION}

We will construct a model of human weight correction of height $170 \mathrm{~cm}$, age 23 weighing $77 \mathrm{~kg}$. The authorized user in the system of human body weight correction has his own personal cabinet in which he can put his age, height and weight. Figure 4 shows the user's "Personal Account" page.

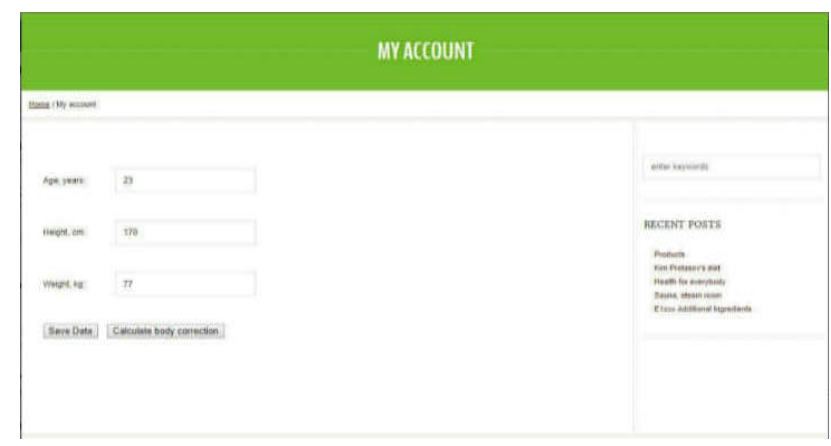

Figure 4 - The user's "Personal Account" page
In accordance with Mifflin-St Jeor formula (1)(2), we calculate the daily calorie intake, which should be used by humans for the normal functioning of the organism. On the basis of calculations, we will represent the interval model (11) for optimal indexes of physical activity $A_{i}, i=\overline{1,2 \ldots 1,9}$. For each index of human physical activity tolerances of lower and upper values of daily calorie norm are known. In particular, for the indicator of physical activity 1,2 the daily calorie value is $[1867,8 ; 1992,6]$, for the indicator 1,375 [2140,2;22 10], etc. Therefore, the interval model (11) will look like:

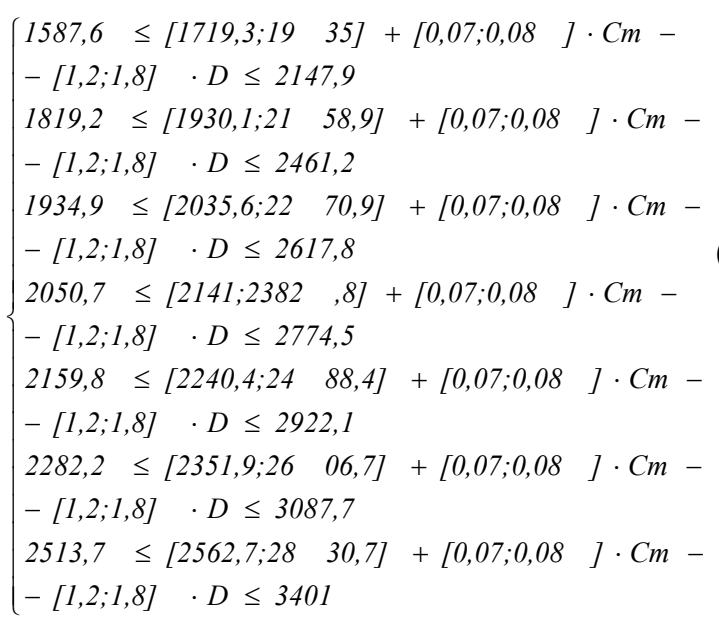

It is necessary to introduce the restrictions on the parameters of the process of body weight correction in order to obtain a set of ISLAE solutions that correspond to the physical content of the processes.

Such restrictions, as the weight loss duration, and the average calorie intake a day, the user can own determine. However, the limits of the minimum number of days needed to achieve normal weight and the maximum number of calories that a user can loss a day of weight loss will be displayed automatically. These indicators, above all, will directly depend on human physical activity

$$
\left\{\begin{array}{l}
10 \leq D \leq 210 \\
1700 \leq C m \leq 3000
\end{array}\right. \text {. }
$$

We obtain the system in the form (14) adding to ISLAE (12) the system of inequalities (13). 


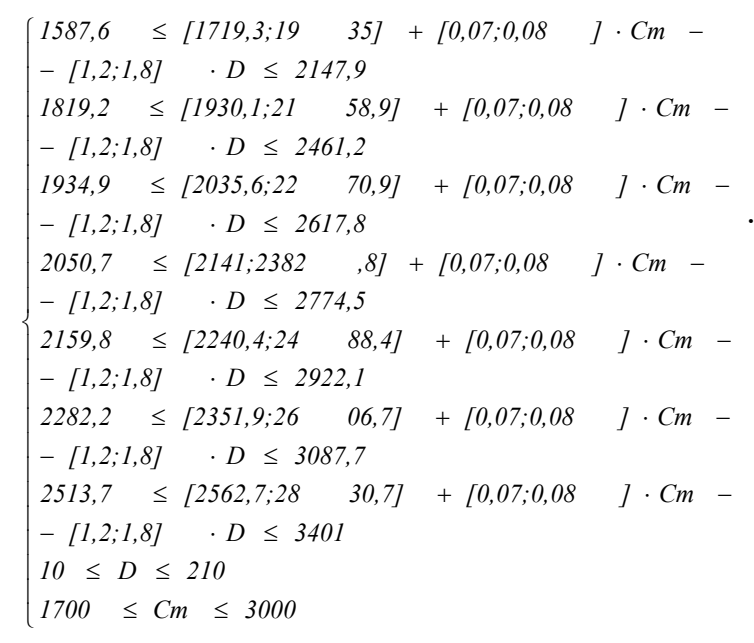

Consequently, system (14) is a model of the process of body weight correction.

After clicking on the button "Calculation of weight correction indicators" the user will be presented with a form for entering the initial values for calculation of unknown parameters of the model of body weight correction by the method of random search.

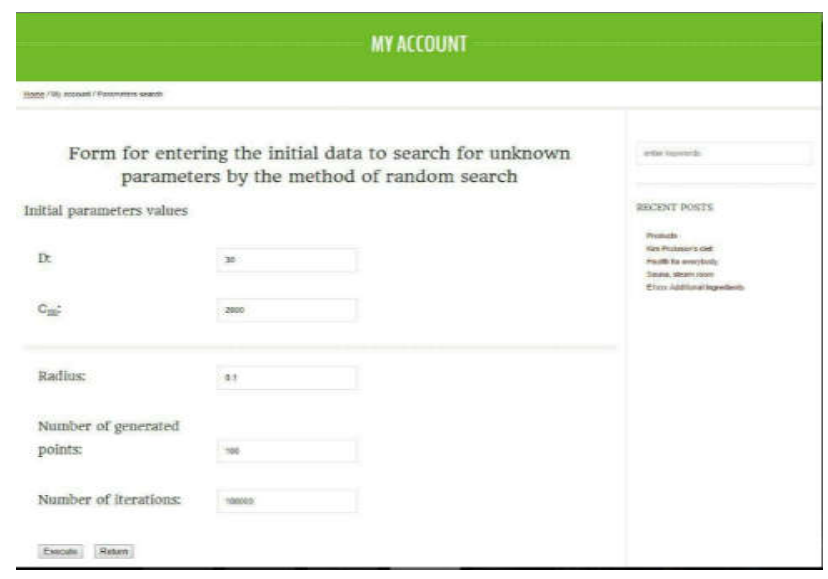

Figure 5 - Formof initial values input for calculation of unknown model parameters

The result of applying the above described method of modeling the body weight correction and the software developed on the basis of the interval data analysis is the vector of the system parameters values. The resulting form of implementation of the method is shown in Fig. 6.

After determining the parameters of the body weight correction model using method of interval data analysis, in particular the number of days for weight loss $D=48$ on average amount of daily calories used $C_{m}=2489$, the user is asked to choose from the set of possible variants of "correct" daily diets. Fig. 7 shows a form with one of the variants for such diet model.

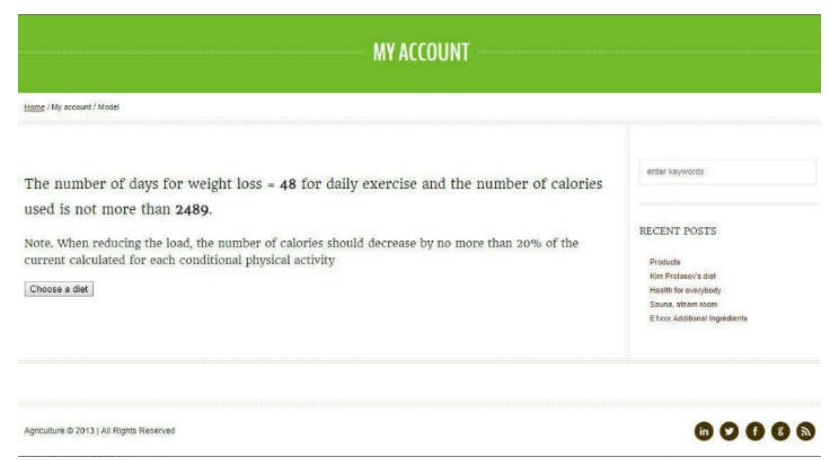

Figure 6 - The representation form of the vector of system parameter values

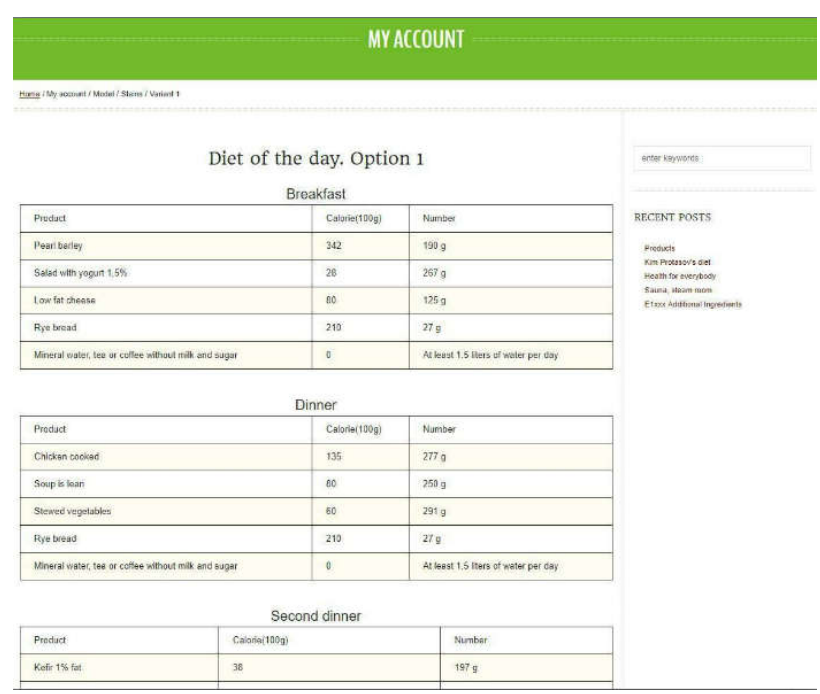

Figure 7 - The form of the proposed daily mode of rational nutrition

As it can be seen in the figure, according to the calculated parameter of the body weight correction model $C_{m}$, the number of calories used a day to achieve a score of normal weight for 48 days is divided between the proposed food and its maximum allowable weight for use [21].

\section{CONCLUSIONS}

The problem of overweight, unfortunately, is increasing every year with ever-growing speed. According to the results of scientific research by 2025 , the world population of obese patients will grow by at least $4 \%$. Therefore, solving this problem is an urgent task. The article presents existing approaches to the treatment of obesity, which includes several stages, including the determination of the normal body weight, the calculation of the main metabolism and the calories consumed / burnt, and the development of a rational day mode too. It is shown that at the moment there are no developed 
models that would allow a person to calculate all the indices necessary to simulate the process of weight correction in one system. The Mifflin-St Jeor formula and the human physical activity coefficient are used to simulate the body weight correction. However, taking into account the error that occurs when a person determines his physical activity coefficient, it is decided to apply methods of interval data analysis to more adequately represent the process of weight correction.

Existing software products, for the most part contain only information on calorie content, different diets, etc.

The formulation of the problem of modeling the process of a human body correction with consideration of restrictions on its initial characteristics is considered. The method of modeling human weight correction with optimization of their parameters on the basis of interval data analysis is developed. The expediency of using the methods of random search based on the interval data analysis which is used for the problem of modeling the process of body weight correction is shown. As a result of using the proposed method, an interval model of the body weight correction process is constructed.

The program complex of modeling the process of human body weight correction is developed. This testing was carried out on the example of determining the parameters of the model of correction of a 23-year-old woman of height $170 \mathrm{~cm}$ weighing $77 \mathrm{~kg}$. It is shown that the woman's normal body weight will be achieved in 48 days with daily training (the coefficient of physical activity should be not less than 1, 6325) and the number of calories consumed a day is not higher than 2489 .

In the software system for calculation parameters of the model of body weight correction, there is the function "Select a diet of the day", which allows you to select from the set of possible rations the most suitable according to the liking, which will already be calculated in accordance with the quantity of the parameters received.

\section{REFERENCES}

[1] History of modern nutrition science implications for current research, dietary guidelines, and food policy [Online]. Available at: https://www.bmj.com/content $/ 361 / \mathrm{bmj}$. k2392 (Accessed 2018-01-17)
[2] The History of Nutrition. [Online]. Available at: $\quad$ https://www.naturalhealers.com/blog/ nutrition-history/ (Accessed 2018-01-17)

[3] T. Voznesenskaya, "Typology of eating disorders and emotional and personality disorders in primary obesity and their correction,"Medical News Agency, no. 9, pp. 234-271, 2004.

[4] C. J. Stein, G. A. Colditz, "The epicemic of obesity," The Journal of Clinical Endocrinology \& Metabolism, vol. 89, issue 6, pp. 2522-2525, June 2004.

[5] Comparison of Harris-Benedict and Mifflin-St Jeor equations with indirect calorimetry in evaluating resting energy expenditure. [Online]. Available at: https://www.ncbi.nlm.nih.gov/pubmed/186881 13 (Accessed 2018-01-17)

[6] Z. S. Warwick, S. S. Schiffman, "Role of dietary fat in calorie intake and weight gain," Neuroscience \& Biobehavioral Reviews, vol. 16, issue 4, pp. 585-596, 1992.

[7] Calorie Labeling and Food Choices: A First Look at the Effect on Low-Income People in New York City [Online]. Available at: https://www.healthaffairs.org/doi/full/10.1377/ hlthaff.28.6.w1110 (Accessed 2018-01-17)

[8] G. Alefeld and J. Herzberger, Introduction to Interval Calculations, Computer Science, and Applied Mathematics, Academic Press, Inc. [Harcourt Brace Jovanovich, Publishers], New York, 1983.

[9] G. Alefeld, G.Mayer, "Interval analysis: theory and applications," Journal of Computational and Applied Mathematics, no. 121, pp. 421464, 2000.

[10] S. Sharyi, Finite-Dimensional Interval Analysis, Novosibirsk, 2009, 569 p.

[11] R. E. Moore, Methods and Applications of Interval Analysis, Philadelphia, "SIAM", 1979, $190 \mathrm{p}$.

[12] S. Kalmykov, Yu. Shokin, Z. Yuldashev, Methods of Interval Analysis, Novosibirsk, "Nauka", 1986, 222 p. (in Russian)

[13] V. Tomashevsky, Systems Modeling, Kyiv, "Publishing Group VNV", 2005, 352 p. (in Ukrainian)

[14] D. Grop, Methods of Systems Identification, Moscow, "Mir", 1979, 302 p. (in Russian) 
[15] J. Rohn, "Input-output model with interval data," Econometrica, vol. 48, pp. 767-769, 1980.

[16] E. Alekseeva, O. Kutnenko, A. Plyasunov, Numerical Methods of Optimization, Novosibirsk, 2008. (in Russian)

[17] M. Abbasov, Optimization Methods, Moscow, "VVM", 2014, 64 p. (in Russian)

[18] E. Hansen, Global Optimization using Interval Analysis Methods, Izhevsk, "Regular and chaotic dynamics", 2012, 516 p. (in Russian)

[19] S. Krepych, A. Dyvak, M. Dyvak, I. Spivak, "The method of providing the functional suitability of the elements of the device of the formation of a signal in the electrophysiological way of classification of tissues of a surgical wound," Proceedings of the XIII-th International Conference on Perspective Technologies and Methods in MEMS Design (MEMSTECH), 2017, pp. 183186.

[20] M. Dyvak, P. Stahiv, I. Kalishchuk, "Algorithm of tolerance identification of "input-output" interval dynamic model," Proceeding of Third 2005 IEEE Workshop IDAACS'2005, Sofia, Bulgaria, 2005, pp. 488-490.

[21] K. Daiber, Table of Product Calorie, Moscow, "My World", 2006, 120 p. (in Russian)
PhD., Iryna Spivak, graduated from Ternopil National Economic University. Now she works as an Associate Professor of Computer Science Department at Ternopil National Economic University.

Research interests: mathematical modeling, numerical methods, interval analysis, optimization techniques.

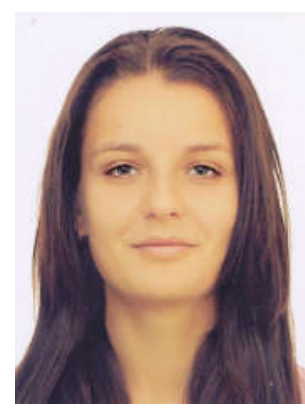

PhD., Svitlana Krepych, graduated from Ternopil National Economic University. Now she works as an Senior Lecturer of Computer Science Department at Ternopil National Economic University.

Research interests: mathematical modeling, numerical methods, optimization techniques, system's functional suitability. 